\title{
Pesticide Uses and its Effects on Public Health and Environment
}

Kalpana Gyawali*

\begin{abstract}
Pesticide's manufacture, use, storage and disposal should be strictly regulated to reduce its negative effects on environment and public health. The reports show that the pesticide use increasing every year globally and currently its national use in average is $0.39 \mathrm{~kg} \mathrm{a}$. i/ha. It has been found that the quantity of consumption of pesticide in Nepal in agricultural field is very low in comparison to the other countries of the globe but due to its haphazard use in some commodity and ignorance of waiting period after its application has increased the risk of the exposure of farm families to pesticides and intake of pesticides by consumers, which are becoming major health threat.
\end{abstract}

Keywords: pesticide, human health, environment

\section{Introduction}

Definition of pesticide varies with time and countries. However, the essence of pesticide remains basically constant, i.e., it is a (mixed) substance that is poisonous and effective to target organisms and is safe to non-target organisms and environments. A pesticide is defined as any substance or mixture of substances intended for preventing, destroying, repelling, or mitigating any pest (insects, mites, nematodes, weeds, rats, etc.), including insecticide, herbicide, fungicide, and various other substances used to control pests (EPA, 2009).

Different chemicals have long been used to control pests. Sumerians already employed sulfur compounds to control insects and mites 4500 years ago. Pyrethrum, a compound derived from the dried flowers of Chrysanthemum cinerariaefolium, has been applied as an insecticide for over 2000 years. Salt or sea water has been used to control weeds. Inorganic substances, such as sodium chlorate and sulfuric acid, or organic chemicals derived from natural sources were widely employed in pest control until the 1940s (Unsworth 2010). Identification of Dichloro Diphenyl Trichloroethane (DDT) as a potential pesticide by Paul Herman
Muller in 1939, for which a Nobel Prize was awarded, opened the doorto the extensive use of the chemicals for various purposes. During World War II (1939-1945), the development of pesticides increased, because it was urgent to enhance food production and to find potential chemical warfare agents. Consequently, the1940s witnessed a marked growth in synthetic pesticides like DDT, aldrin, dieldrin,endrin, parathion, and 2,4-D. In the 1950s, the application of pesticides in agriculture was considered advantageous, and no concern about the potential risks of these chemicals to the environment and the human health existed at that time.

In Nepal, during the 1950s, DDT was introduced for malaria eradication program which was later imported by the Government of Nepal. Later on, other pesticides like Gammexene and nicotine sulfates were imported for the same purpose. Gradually, new kinds of pesticides like organochlorines, organophosphates and carbamates and syntheticpyrethroids were introduced for agricultural, public health and other purposes. The worldwide consumption of pesticides is about two million tons per year and out of which $45 \%$ is used by Europe alone, $25 \%$ is consumed in the USA, and $25 \%$ in the rest of the world (EPA,2011

* Lecturer, Sanothimi Campus, Bhaktapur 
cited in Dhital et al, 2015). Despite their benefits, pesticides can be hazardous to both humans and the environment. In 1962, Rachel Carson published the book "Silent Spring", in which she mentioned problems that could arise from the indiscriminate use of pesticides. This book inspired widespread concern about the impact of pesticides on the human health and the environment. In the 1970s, pest resistance emerged and combined with influence of the book "Silent Spring", and accumulated evidence on the effects of pesticides, culminated in banning of the use of DDT in the United States in 1972. Thereafter, other countries discontinued the use of DDT, as well (Lengoods et al, 2007, cited in Bernands et al., 2015). Some other pesticides are also environmentally stable, prone to bioaccumulation, and toxic can persist in the environment, they can remain there for years. Environmental contamination or occupational use of pesticides can expose the general population to pesticides residues (Mostafalou, et al., 2013).

\section{Methodology}

This report is based on the review of secondary information published by the relevant organization and authors in Nepal and beyond. Especially the data are been reviewed from Plant Protection Directorate (Department of Agriculture), Pesticide Regulation and Management Program, Food and Agriculture Organization, Pesticide Action Network and World Health Organization's website and publications. The research reports of different national and international journal that is available on online also have been accessed and reviewed to prepare the report .

\section{Result and Discussion}

\section{Global Consumption of Pesticide}

Pesticide is one of the major inputs in modern agriculture and its uses is increasing annually. Around in 2007, about 2363 million kg of pesticides was used in the world with herbicides constituting the highest share of 950.7 million $\mathrm{kg}$ followed by 404.6 million $\mathrm{kg}$ of insecticides followed by 262.17 million $\mathrm{kg}$ of fungicides. Other pesticides like nematicides and fumigants etc also constituted the share of 773.37 million $\mathrm{kg}$ (EPA, 2011 cited in Dhital et al, 2015). Though world average uses of pesticide is 0.5 $\mathrm{kg}$ ai/ ha (PPD, 2015), but some industrial and developed countries use pesticide more than world average and it is upto $17 \mathrm{~kg}$ in Taiwan, $14 \mathrm{~kg}$ in Republic of Korea, $12 \mathrm{~kg}$ in Japan, $9.4 \mathrm{~kg}$ in Netherlands and $7 \mathrm{~kg}$ in the USA . The average use of pesticide in the Nepal is far below than those developed countries and also below the global average and it is $0.396 \mathrm{~kg}$ a.i./ ha (Table 1). But the pesticide use in certain crop like in vegetable is higher than national average that is $1.6 \mathrm{~kg}$ a.i/ha (PPD,2015) in Nepal.

Table 1. Status of pesticide use in selected countries ( $\mathrm{kg}$ a.i/ha)

\begin{tabular}{ll}
\hline \multicolumn{1}{c}{ Country } & $\begin{array}{l}\text { Pesticide use } \\
\text { (a.i. kg/ha) }\end{array}$ \\
\hline Japan & 12 \\
Netherlands & 9.4 \\
USA & 7 \\
India & 0.5 \\
Taiwan & 17 \\
France & 5 \\
Republic of Korea & 7 \\
China & 14 \\
& 0.396 (National \\
Nepal & average) \\
& 1.6 (vegetable) \\
\hline
\end{tabular}

Source: (Arora et al., 2011)

\section{Pesticide consumption in Nepal}

The domestic consumption of pesticide in Nepal is lower i.e. 0.392 a.i. $\mathrm{kg} / \mathrm{ha}$ (kilogram per hectare) (PPD, 2015) as compared to other developed countries. Among different pesticides, fungicide is the dominant form of 
pesticides used in Nepal. In the year 2016/17, more than $43 \%$ of pesticides were used in the form of fungicides followed by insecticide (31.58\%) and herbicide (23.38\%).The share of rodenticide, bactericides and bio pesticide is very low as compared to above mentioned pesticide and it shares $1.91 \%, 0.01 \%$ and $0.001 \%$ respectively (PRMP,2073). Total active ingredients used in the pesticides during 2015/16 were about 574 metric tons $\mathrm{kg}$ or liters of which very minimal amount has been used for public health that is about $174 \mathrm{mt}$ ( Table 2).

Table 2. Share of different types of pesticide imported or formulated in FY 2015/16 in Nepal

\begin{tabular}{lll}
\hline $\begin{array}{l}\text { Types of } \\
\text { pesticide }\end{array}$ & $\begin{array}{l}\text { Active } \\
\text { (MT) }\end{array}$ & ingredient \\
\hline Insecticides & 181.27 \\
Fungicides & 247.475 \\
Bacteriacides & 0.011 \\
Herbicides & 134.232 \\
Rodenticides & 11 \\
Biopesticides & 0.063 \\
Total & 574.06 \\
\hline
\end{tabular}

Source: PRMP, 2073

Until the 1950s, the people of Nepal remained unaware of modern chemical pesticides and were dependent upon traditional organic techniques for killing pests. Chemical pesticides were first introduced to Nepal in 1952, when Paris green, Gammaxene, and Nicotine sulphates were imported from the USA for malaria control. DDT made its first appearance in 1956. This was soon followed by a variety of other organochlorines (in 1950s), organophosphates (in 1960s), carbamates (in 1970s), and synthetic pyrethroids (in 1980s) (Koirala et al., 2009b). Along with the green revolution and malaria control program, pesticides started to use in agriculture and public health purpose and after that the trend of pesticide use is increasing in Nepal (PRMP, 2073) (Figure 1). Studies have shown that more than $90 \%$ of the total pesticides are used in vegetable farming (Atreya and Sitaula, 2011). Another study showed that chemical pesticides are used by $25 \%$ of Terai households, $9 \%$ of mid Hill households and 7\% of Mountain households (Sharma et al., 2012). In certain mid hill pockets close to urban markets, the pesticide use is considerably higher. In Nepal, organ chlorine was more popular in the past and organophosphate at present (PRMP, 2073).

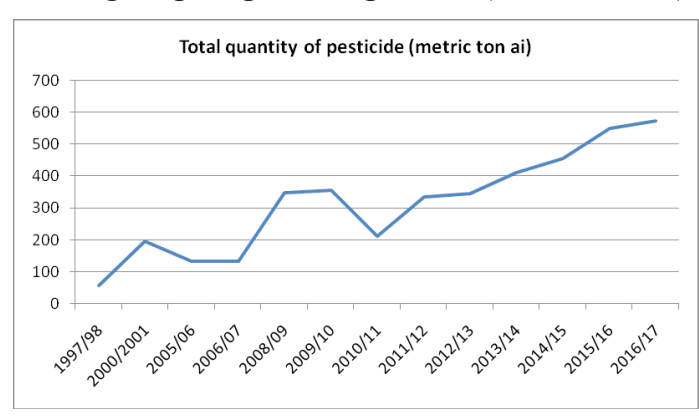

Figure 1. Total imported and formulated pesticide in Nepal during different time span.

\section{Source: PRMP (2073)}

Along with the increasing consumption pesticides, its misuse is another major problem in Nepalese environment and public health. Especially the uses of broad spectrum pesticide cause pests to adapt and become resistant to the pesticides (Yadav and Lian, 2009, cited in Sharma et al., 2012)). Then it requires at higher doses to achieve the same level of control. Farmers generally do not follow the pre-harvest waiting period too. They apply pesticides near harvesting time, and some farmers even dip vegetables in pesticides before selling (Sharma et al., 2012). Misuse of insecticides is common in Nepal. Unregistered and illegal products, open air sales, sales of banned products, cases of decanting and reweighing, fake pest control products using counterfeit labels, sales of expired products with modified expiry dates are among the misuse cases that have been reported in Nepal. 
Effects of pesticide on human health and environment:

Pesticide has both beneficial and harmful effect for human and environment.

\section{a) Beneficial effects}

i) Improve production and productivity of agriculture commodity to feed the ever growing population,

ii) Control vector borne disease like malaria and reduce mortality and morbidity and make better place to live, and

iii) Other like sports (cricket ground, golf lawn), road, building (against termites) etc.

\section{b) Harmful effects}

Pesticides are designed to kill pests, but some pesticides can also cause negative health effects in people and damage ecosystem. Pesticide residues absorbed by inhalation, ingestion, and dermal contact can lead to acute and chronic toxicity. Such kinds of the toxicity depend on types of pesticides, port of entry, dose, metabolism, accumulation and so on. Acute toxicity is due to short-term exposure and happens within a relatively short period of time, whereas chronic toxicity is due to repeated or long-term exposure and happens over a longer period. Mainly it interrupts the metabolic and systemic functions of the human body. The chemical compound of pesticide disrupts the neurological function. It is injurious to the immune and endocrine systems as well (Wesseling, et al., 1997).

Wide use of these pesticides can cause both acute and chronic adverse health effects in human. Studies in the past have revealed the association of organochlorine and organophosphate with diabetes mellitus (Paudayl, 2008). Organophosphate inhibits the neurotransmitter acetyl cholinesterase and can affect the central and autonomic nervous system. Few leading symptoms related to the autonomic nervous system are abdominal cramps; nausea, diarrhea, salivation, miosis and symptoms related to the central nervous system are dizziness, tremor, anxiety, and confusion. Symptoms usually occur within hours of exposure and typically disappear within days or weeks as new cholinesterase is synthesized (Aryal et.al., 2016). In many developing countries like Nepal, most pesticides are associated with adverse effects on human health and environment due to inappropriate use and handling of pesticides by inadequately trained farm workers (Naidoo et al., 2010). Majority of pesticides users, being unaware of pesticide types, their mode of action, potential hazards and safety measures, and the problem is becoming more havoc.

The pesticides are widely applied in agriculture sector of Nepal. Farmer had considerable knowledge regarding health impacts of pesticide; however, they did not adopt the safety precaution resulting higher risk of exposure with pesticide intoxication. As a result, nearly $51 \%$ farmers experienced an acute toxicity syndrome of pesticides and one of ten farmers reported several kinds of chronic diseases of which 24\% farmers had chronic neuropathic diseases (Aryal et.al., 2016).

The other major harmful effects of pesticide in human and environment are:

\section{Direct impact on human}

The credits of pesticides include enhanced economic potential in terms of increased production of food and fiber, and management of vector-borne diseases, and then their debits have resulted in serious health implications to man and environment. There is now overwhelming evidence that some of these chemicals do pose a potential risk to humans and other life forms and unwanted side effects to the environment (Forget, 1993; Igbedioh, 1991; Jeyaratnam, 1981 cited in Aktar et.al., (2009)). 
No segment of the population is completely protected against exposure to pesticides and the potentially serious health effects. Accurate statistics on health effects of pesticides are not available. However, it is estimated that globally, every year, between 1 and 41 million people suffer from exposure to pesticides (PAN International, 2007).WHO (2009) estimated that a minimum of 300,000 people die from pesticide poisoning each year, with $99 \%$ of them from low- and middle- income countries. In 2008, the World Bank put the number of deaths at 355,000. However, FAO (2005) referring to recent data from Sri Lanka indicated that 300,000 deaths per year may occur in the Asia-Pacific region alone due to pesticide poisoning.The epidemiology of pesticide exposure globally is not fully understood and most of the time underdiagnosed, according to the Pan American Health Organization, an international public health agency based in Washington, D.C. "Pesticide poisoning cases are under-reported by 50 percent to 80 percent regionwide," reported the PAHO in 2011, referring to the Americas.

\section{Impact on environment}

Pesticides have severe impact on environment too. Some are mentioned below:

i) Surface and ground water contamination:

Pesticides are included in a broad range of organic micro pollutants that have ecological impacts. Different categories of pesticides have different types of effects on living organisms, therefore generalization is difficult. Although terrestrial impacts by pesticides do occur, the principal pathway that causes ecological impacts is that of water contaminated by pesticide runoff. The two principal mechanisms are bio concentration and bio magnification.

Bio concentration: This is the movement of a chemical from the surrounding medium into an organism. The primary "sink" for some pesticides is fatty tissue ("lipids"). Some pesticides, such as DDT, are "lipophilic", meaning that they are soluble in, and accumulate in fatty tissue such as edible fish tissue and human fatty tissue. Other pesticides such as glyphosate are metabolized and excreted.

Bio magnification: This term describes the increasing concentration of a chemical as food energy is transformed within the food chain. As smaller organisms are eaten by larger organisms, the concentration of pesticides and other chemicals are increasingly magnified in tissue and other organs. Very high concentrations can be observed in top predators, including man.

The ecological effects of pesticides and other organic contaminants are varied and are often inter-related.Pesticides can contaminate soil, water, turf, and other vegetation. In addition to killing insects or weeds, pesticides can be toxic to a host of other organisms including birds, fish, beneficial insects, and non-target plants. Ecological effects of pesticides extend beyond individual organisms and can extend to ecosystems. Swedish work indicates that application of pesticides is thought to be one of the most significant factors affecting biodiversity. WWF reports that the increased rate of disease, deformities and tumors in commercial fish species in highly polluted areas of the North Sea and coastal waters of the United Kingdom since the 1970s is consistent with effects known to be caused by exposure to pesticides (FAO, 1996).

Pesticidescanreachsurface waterthroughrunoff from treated plants and soil. Contamination of water by pesticides is widespread. The results of a comprehensive set of studies done by the U.S. Geological Survey (USGS) on major river basins across the USA in the early to mid- 90s have shown the alarming situation that is more 
than 90 percent of water and fish samples from all streams contained one, or more often, several pesticides (Kole et al., 2001).

Similarly, groundwater pollution due to pesticides is a worldwide problem. According to the USGS, at least 143 different pesticides and 21 transformation products have been found in ground water, including pesticides from every major chemical class . During one survey in India, 58\% of drinking water samples drawn from various hand pumps and wells around Bhopalwere contaminated with Organo Chlorine pesticides above the EPA standards (Kole and Bagchi, 1995 cited in Aktar et al., 2009 ). Once ground water is polluted with toxic chemicals, it may take many years for the contamination to dissipate or be cleanedup. Cleanup may also be very costly and complex, if notimpossible (Waskom 1994; O’Neil, 1998; US EPA, 2001 cited in Aktar et al.,2009).

\section{ii) Soil contamination}

Different pesticides used in soil treatment and also large number of transformation products (TPs) from a wide range of pesticides can cause populations of beneficial soil microorganisms to decline. According to the soil scientist Dr. Elaine Ingham, "If we lose both bacteria and fungi, then the soil degrades. Overuse of chemical fertilizers and pesticides have effects on the soil organisms that are similar to human overuse of antibiotics. Indiscriminate use of chemicals might work for a few years, but after a while, there aren't enough beneficial soil organisms to hold onto the nutrients" (Savonen, 1997). The loss of beneficial microorganisms in soil will cause low fertility of the soil and will be responsible for poor production and productivity of crops. And it ultimately reduces the farm income and enhances hunger and poverty.

\section{iii) Contamination of air and non-target vegetation}

Pesticide sprays can directly hit non-target vegetation, or can drift or volatilize from the treated area and contaminate air, soil, and non-target plants. Some pesticide drift occurs during every application, even from ground equipment (Glotfelty and Schomburg, 1989). Drift can account for a loss of 2 to $25 \%$ of the chemical being applied, which can spread over a distance of a few yards to several hundred miles. As much as $80-90 \%$ of an applied pesticide can be volatilized within a few days of application (Majewski, 1995). This contamination will make negative effect to non-targeted fauna and flora and disturb the ecosystem. This imbalanced ecosystem influences socio economic aspect of human beings along-with health status.

\section{Government Initiatives to regulate pesticide in Nepal:}

Government of Nepal (GON) is the signatory of Stockholm Convention, Basel Convention and Rotterdam Conventions to minimize environment pollution and to manage agrochemicals, including pesticides. Government has accorded high priority to integrated pest management (IPM) to minimize pesticide risk (PPD, 2008). Government of Nepal has banned and restricted 16 different pesticides due to their high risk for human health and environment $\left(\mathrm{la}=\mathrm{k}=\mathrm{Jo}_{\mathrm{O}}=\mathrm{Zf}=@\right) \& \#$.

The following is a senario of the result of RBPR analysis unit, Kalimati, Kathmandu regarding the completion of Rapid Bioassay of pesticides residue analysis.

\section{Source: PPD, 2016}

The ascending trends of pesticide uses and its increasing havoc, Ministry of Agriculture Development has established Rapid Bioassay of pesticide Residue Analysis Laboratory at Kalimati wholesale market at Kathmandu in 2071B.S. The sample is collected from different vegetable and fruit lots which are brought to wholesale market from different parts of the country and from aboard and 
Table 3. Year-wise completion of Rapid Bioassay of pesticide residue analysis

\begin{tabular}{llllll}
\hline Years & Commodity & $\begin{array}{l}\text { Inhibition percentage } \\
<35 \% \text { (Green) }\end{array}$ & $\begin{array}{l}35-45 \% \\
\text { (Yellow) }\end{array}$ & $>45 \%$ (Red) & Remark \\
\hline \multirow{2}{*}{$2071 / 72$} & Vegetable & 146 & 4 & 25 & $\begin{array}{l}\text { Before RBPR } \\
\text { establishment }\end{array}$ \\
& Fruit & 9 & 2 & 1 & \\
$2071 / 72$ & Vegetable & 1457 & 15 & 4 & \\
& Fruit & 36 & 0 & 0 & \\
$2072 / 73$ & Vegetable & 1883 & 8 & 10 & \\
& Fruit & 35 & 0 & 0 & \\
$2073 / 74$ & Vegetable & 1875 & 5 & 21 & \\
& Fruit & 29 & 0 & 0 & \\
\hline
\end{tabular}

analyzed for pesticide residue. The result show that most of the sample are safe to eat (i.e $<35 \%$ ) and the inhibition level is below $35 \%$. Those samples which had more than 45 $\%$ inhibition percentage were vegetables. After establishment of RBPA laboratory the number of sample with higher inhibition percentage (i.e. $>45 \%$ ) is decreasing and it is good news for consumer (PPD, 2074) (Table 3).

\section{Conclusion}

Pesticides are often considered a quick, easy, and inexpensive solution for controlling weeds and insect pests in agriculture, public health and other areas. However, pesticide use comesat a significant cost. Pesticides have contaminated almost every part of our environment. Pesticide residues are found in soil and air, as well as in surface and ground water across the countries, and contamination poses significant risks to the human health as well as environment and non-target organisms ranging from beneficial soil microorganisms to insects, plants, fish and birds. Since 1950s, pesticides have been used for increasing the agricultural productivity and safeguarding the public health in Nepal. Every year the consumption of pesticide for agriculture purpose is increasing. Though the quantity of consumption per hectare in agricultural field is very low comparing with other countries of the globe but due to haphazard use of pesticide in some commodity and ignorance of waiting period after its application has increased the exposure of farm families to pesticides and intake of pesticides by consumers, which are becoming major health threat. Injudicious and indiscriminate use of pesticides and presence of pesticide residues in food, fruits, vegetables and environment is a matter of grave-concerns in our context.

To sum up, based on our limited knowledge of direct and/or inferential information, the domain of pesticides illustrates a certain ambiguity in situations in which people are undergoing life-long exposure. There is thus every reason to develop health education packages based on knowledge, aptitude and practices and to disseminate them within the community in order tominimize human exposure to pesticides. Taking into consideration the health and environmental effects of chemical pesticides, it is clear that the need for a new concept in agriculture is urgent. This new concept must be based on a drastic reduction in the application of chemical pesticides, which can result in health, environmental, and economic benefits to the public. 


\section{REFERENCES}

Arora, S., Kapoor, A. K. \& Bambawale, O.M. (2011). Pesticides: Status, latest WHO ranking, regulation and label claims in India. New Delhi: National Centre for Integrated Pest Management, Indian Council for Agricultural Research, IARI, Pusa Campus.

Aktar, M.W., Sengupta, D., \& Chowdhary, A. (2009). Impact of pesticides use in agriculture: their benefits and hazards Interdisc Toxicol. 2009; Vol. 2(1): 1-12. Retrieved from doi: 10.2478/v10102-0090001-7

Aryal, K.K., Neupane, S., Lohani, G.R., Jors, E., Neupane, D., Khanal, P.R., Jha, B.K., Dhimal, M., Shrestha, B.M., Bista, B., Poudyal, A., Karki, K.B. (2016). Health Effects of Pesticide among Vegetable Farmers and the Adaptation Level of Integrated Pest Management Program in Nepal, 2014. Kathmandu, Nepal: Nepal Health Research Council, 2016.

Atreya, K, Sitaula, B.K., Mancozeb. (2011). Growing risk for agricultural communities? Himalayan Journal of Sciences. 6(8): 9-10.

Bernardes, M.F.F., Pazin, M., Pereira, L.L., and Dorta, D.J. (2015). Impact of Pesticides on Environmental and Human Health, Toxicology Studies-Cells, Drugs and Environment, Dr. Ana Cristina Andreazza (Ed.), In Tech, Retrieved from DOI: 10.5772/59710. https://www.intechopen. com/books/toxicology-studies-cells-drugsand-environment/impact-of-pesticides-onenvironmental-and-human-health

Dhital, S., Rupakheti, D., Tripathi, L., Sigdel, S.R. (2015). A review on status of pesticide use in Nepal. Research Journal of Agriculture and Forestry Sciences. 3(3), 26:29
EPA. (2009). What is a pesticide? Retrieved from http://www.epa.gov/opp00001/about/

FAO. (1996). Control of water pollution from agriculture - FAO irrigation and drainage paper 55. Retrieved from http://www.fao. org/docrep/w2598e/w2598e07.htm

FAO. (2005). Proceedings asia regional workshop on the implementation, monitoring and observance of the international code of conduct on the distribution and use of pesticides. Bangkok, Thailand, 26-28. Retrieved from https:// ensia.com/features/developing-worldpesticides/ July 2005.

Glotfelty, J., and Schomburg, J. (1989). Volatilization of pesticides from soil in Reactions and Movements of organic chemicals in soil. Eds.BL Sawhney and K. Brown. Madison, WI: Soil Science Society of America Special Pub.

Koirala, P., Dhakal, S., Tamrakar, A.S. (2009). Pesticides and Food Safety Issues in Nepal, The Journal of Agriculture and Environment, Ministry of Agriculture and Cooperatives, 10:96-100.

Majewski, M. \& Capel, P. (1995). Pesticides in the atmosphere: Distribution, trends, and governing factors. Volume one, Pesticides in the Hydrologic System. Ann Arbor Press Inc: 118.

Mostafalou, S., Abdollahi, M. (2013). Pesticides and human chronic diseases: Evidences, mechanisms, and perspectives. Toxicology and Applied Pharmacology 2013; 268:157-177. www document Retrieved from http://dx.doi.org/10.1016/j. taap.2013.01.025

PAN International. (2007). A position on synthetic pesticide elimination: A PAN international position paper-working Group 1. Pesticide action network international. Retrieved from http:// 
www.pan-international.org/panint/ files/WG1\%20Eliminating $\% 20$ the $\% 20$ Worst $\% 20$ Pesticide.pdf.

Paudyal, B.P. (2008). Organophosphorus poisoning. Journal of Nepal Medical Association. 2008; 47(172): 251-258.

PRMP. (2012). Final report on pesticide consumption statistics in Nepal, Mount Digit Technology (P.) Ltd. Ekantakuna Kathmandu

PPD. (2016). Year wise completion of rapid bioassay of pesticide residue analysis results of RBPR analysis unit, Kalimati Retrieved from http://ppdnepal.gov. np/downloadfile/Compilation $\% \quad 20 \mathrm{of} \%$ 20RBPR\%20Result\%202071\%20to\%20 till\%20073-74_1500877179.pdf

Savonen, C. (1997). Soil microorganisms object of new OSU service. Good fruit grower. Retrieved from http: //www. goodfruit.com/archive/ 1995/6other.html.

Sharma, D.R., Thapa, R.B., Manandhar, H.K., Shrestha, S.M., \& Pradhan, S.B. (2012) Use of pesticide in Nepal and impacts on human health and environment. The Journal of Agriculture and environment. 13: 67-74
Unsworth-History of pesticide use. International Union of pure and applied chemistry (IUPAC). (2010). Retrieved from http://agrochemicals.iupac. org/index.php? option=com_so bi $2 \&$ sobi2 Task $=$ sobi2Details $\&$ catid $=3 \&$ so bi2Id $=31$

Wesseling, C., McConnell, R., Partanen, T., Hogstedt, C. (1997). Agricultural pesticide use in developing countries: health effects and research needs. Int $J$ Health Serv 27: 273-308. Retrieved from doi: 10.2190/ E259-N3AH-TA1Y-H591

WHO. (2009). World Health Organization, Regional Office for South-East Asia. Health implications from monocrotophos use: a review of the evidence in India. New Delhi. Retrieved from http://203.90.70.117/ PDS DOCS/B4293.pdf.

बि.प.व्य.शा. (२०७३), पज्जिकृत विषादीहर्को अध्यावधिक सूची विषादीपज्जिकरण तथा व्यवस्थापन शाखा हरिहर भवन, ललितपुर । 